\title{
A Descriptive Analysis of Disagreement Strategies: The Case of Iranian EFL Learners
}

\author{
Atieh Farashaiyan \\ School of Language Studies and Linguistics, University Kebangsaan Malaysia \\ 43600, UKM Bangi, Selangor, Malaysia \\ Tel: 60-176-801-267Ｅ-mail: atieh_farashaiyan@yahoo.com \\ Paramasivam Muthusamy (Corresponding author) \\ Department of Foreign Languages, University Putra Malaysia \\ Jalan UPM, 43400 Serdang, Selangor,Malaysia \\ Tel: 60-123-144-600Ｅ-mail: param.muthusamy@yahoo.com
}

Received: Sept. 14, 2016 Accepted: Sept. 20, 2016 Published: October 31, 2016

doi:10.5296/ijl.v8i5.10254ＵRL: http://dx.doi.org/10.5296/ijl.v8i5.10254

\begin{abstract}
The purpose of this research was to describe the L2 pragmatic knowledge of Iranian EFL learners by producing the speech act of disagreement in English in different situations. One hundred and twenty Iranian EFL learners took part in this study. The required data were accumulated through a Written Discourse Completion Task (WDCT). The results showed that most participants tended to make use of more indirect strategies (44.85\%) to disagree with another speaker's statement either with higher or lower power or within different social distance. The respondents' most frequent strategy use refers to counterclaims with $44.8 \%$. On the other hand, challenges with $8.8 \%$ and Irrelevancy of claims with $3.2 \%$ were respectively among the least frequent strategies used in all situations. The results showed that learners almost utilized the same strategies in different disagreement situations with the same frequency. Therefore, it indicates that they did not notice the situational variables of social power, distance and imposition to vary their choice of strategy. In other words, they did not have the contextual understanding of the mentioned factors. Therefore, the results can suggest that the learners lack sufficient pragmatic knowledge in performing the studied speech act. The implication of this study is for Iranian language instructors, materials writers and
\end{abstract}


curriculum developers.

Keywords: Iranian EFL learners, L2 pragmatic knowledge, Disagreement, Speech act, Production 


\section{Introduction}

Communication among individuals from diverse cultures is an everyday phenomenon in recent decades due to the globalization, academic exchanges, tourism and multiculturalism around the world. Such intercultural encounters are inevitable, especially in this multicultural world where there exist a variety of ethnic groups. Therefore, there should exist a shared channel for the purposes of intercultural encounters. So, the English language occupies a fundamental position in this perspective and it is considered as shared vehicle among an assortment of cultures. Since individuals should understand each other's speech in the act of communication in order to convey the intended meaning, therefore the matter of appropriate intercultural understanding of speech becomes important among interlocutors (Al-Zumor, 2011; Dastjerdi \& Farshid, 2014). Thus, in order to understand the intended meaning in communication, the appropriate use of language is an essential component of every intercultural interaction. It is worth mentioning that the use of the English language is accentuated more in EFL contexts since EFL learners are necessitated to make use of the English language for their interactive purposes. These needs include doing their business with other communities, searching and reading scientific articles, applying for diverse jobs in other countries, furthering their education in English-speaking countries or in countries where there are frequent use of the English language and so on.

According to Kachru (1996), Iran is situated in the Expanding Circle Countries (ECC) like Japan and Korea, where English is considered as the Foreign Language (EFL) as contrary to outer circle countries which English is used as a Second Language (ESL) like Malaysia and inner circle countries such as U.S., Canada, and Australia where English is utilized as the First Language. Iranians learn English language as the dominant foreign language to connect and interact with other communities worldwide.

Moreover, it is important to know that Iran as a foreign language context does not provide EFL learners sufficiently to have contact with the English language and culture outside the classroom setting and learners have to depend on classroom learning (Allami \& Naemi 2011). As such, the majority of Iranian students (primary, secondary, high school, and university students) and even other individuals with diverse educational levels and majors with different ages prefer to go to private language institutes to study and learn English to practice it more there (Farhadi et al. 2010; Hosseini 2007). In this way, private language institutes have taken the responsibility to satisfy people's needs to learn English (Shoarinejad 2008).

\subsection{Statement of the problem}

When speakers from diverse socio-cultural backgrounds interact with each other, they may not comprehend another interlocutor's speech or intended meaning and as a result, cross-cultural misunderstanding may take place in some specific situations between people with diverse socio-cultural backgrounds. This quandary is considered as the one of the problems that EFL learners, especially Iranian learners of English face when they communicate interculturally with other individuals (Derakhshan \& Zangoei, 2014). In fact, the main problem Iranian learners of English encounter in the act of intercultural communication is pertinent to pragmatic-rooted one related to the appropriate use of language 
(Gahrouei, 2013). Therefore, it can be claimed that the most fundamental cause of misunderstanding between cultures is concerned with the pragmatic breakdown in opting out the proper speech act strategies (Kia \& Salehi, 2013). As such, to eschew intercultural misapprehensions and the consequential pragmatic breakdown in the act of interaction, L2 pragmatic knowledge of EFL learners or speakers should be sufficiently developed so that they can cross their intended meaning to other interlocutors. This issue can give rise to more efficient and prosperous intercultural communication (Lin, 2014; Salehi, 2013.).

Since the classroom context is the sole place that Iranian learners learn the English language, therefore second language acquisition researchers have been inspired to examine the current position of L2 pragmatic knowledge of Iranian learners of the English language in language classrooms and investigate the development of learners' pragmatic knowledge in EFL contexts (Sabzalipour, 2013; Tamjid \& Noroozi, 2014). In addition, the review of research literature of L2 pragmatics in EFL contexts has illustrated that the most researches done were intercultural studies which made a comparison between the pragmatic production of English native speakers with non-native English speakers in terms of the understanding and producing the strategies of speech acts. As such, there is a dearth of research to examine the development of pragmatic competence in EFL contexts. Therefore, this study tries to fill this gap by examining L2 pragmatic knowledge of Iranian learners (both pragmalinguistic and sociopragmatic knowledge) via performing and producing the speech act of English disagreement in various situations. This study employed two theoretical models, i.e., the speech acts theory of Austin (1962), the politeness theory of Brown and Levinson (1987).

\section{Method}

\subsection{Participants}

The subject of this research included one hundred and twenty Iranian EFL learners whose language proficiency was at the intermediate level. After the administration of OPT placement test, 120 learners were chosen as intermediate level learners according to the test results and the reminders were eliminated from the research. The whole participants were female since the gender was not considered as a variable in this research and their age ranged between 25 to 40 years old.

\subsection{Instruments}

For the accumulation of the necessary data for the purpose of this research, a Written Discourse Completion Task or Test (WDCT) was employed in this study. This questionnaire is an international recognized and most common employed questionnaire for evaluating L2 pragmatic knowledge of learners. This questionnaire was utilized in this research for some reasons. First, given that the purpose of this study was to evaluate the pragmatic knowledge of learners, the most effective instrument to achieve necessary data is by means of this questionnaire. Secondly, the preparation and administration of this type of questionnaire for a bulky number of participants need less time. Thirdly, more time is allocated to subjects to think about the situations and the given responses and they may employ diverse strategies compared to other instruments. The questionnaire of this study was 
adapted from Kreutel (2007). The situational variables of social power, distance, and imposition/severity were inserted in the situations of the questionnaire.

Disagreement is considered as dispreferred or undesired reactions which likely results in discomfort feelings. Brown and Levinson (1987) defined disagreement as a speech act in which speaker and hearer attempt to maintain their own positions or statements by opposing each other. It is also considered as a process of opposition which necessitates the approval of other's negative face. Therefore, it is perceived as a face-threatening act which threatens the hearer's positive face and can result in negative social relations. The disagreement WDCT consists of ten scenarios. The scenarios covered different topics and types of situations to avoid intervening effects of topic selection. Moreover, as English was not the participants' native language, the wording of the situations was kept rather simple in order to minimize data distortion caused by incomprehensible input. All situations in the WDCT are of the type "friendly conversation," that is, situations not aiming at dispute in which both parties wish to maintain a relationship and therefore try to save face. The topics and contextual variables are shown in the table below.

Table 1. Topics and situational variables of disagreement situations

\begin{tabular}{rlccc}
\hline Item & Topic & $\begin{array}{c}\text { Variable } \\
\text { Imposition }\end{array}$ & $\begin{array}{c}\text { Variable } \\
\text { Status }\end{array}$ & $\begin{array}{c}\text { Variable } \\
\text { Distance }\end{array}$ \\
\hline 1 & Shopping with two friends & + & $=$ & - \\
2 & Friend's mistake about U.S states & + & $=$ & - \\
3 & Idea about teacher's opinion & + & + & + \\
4 & Roommates mistake about her turn cleaning & - & $=$ & - \\
& room & & & + \\
5 & Disagreement with a friend about vacation spot & + & $=$ & - \\
6 & Opinion about friend's cooking & + & + & + \\
7 & Landlord's mistake about rent payment & + & $=$ & - \\
8 & Friend's mistake in giving directions & + & + & - \\
9 & Disagreement with a friend about a movie & + & + & + \\
10 & Teacher forgetting your assignment & - & + & + \\
\hline
\end{tabular}

Considering the validity of the questionnaire, four experts approved its validity by checking both the content and face validity of the questionnaire. Regarding the reliability of the questionnaire, the inter-rater reliability was performed. The inter-rater reliability estimate for the questionnaire was achieved at around $0.90 \%$ which is an acceptable index.

\subsection{Data Collection Procedure}

The procedure of data collection was conducted at the classroom sessions of the winter academic semester of 2016 at five private language institutes in Shiraz city, Iran. The sampling procedure was a convenient random sampling. The number of intermediate EFL 
learners was 120 learners. The reason is that the number of subjects should be more than 100 for survey researches (Dornyei, 2007). The data were accumulated at sessions when the classroom instructors let the researcher to do so. First, all the necessary explanations with regard to whole questionnaire were given by the researcher in both the English and Persian languages in order to eschew any misunderstanding by the learners to provide the appropriate answers. The questionnaire had the instruction part. It asked the participants to read ten situations. After each situation, the participants were asked to write a response in the blank after 'You'. in addition, they were supposed to respond as naturally as possible and try to write their response as they feel they would say it in the situation. Then, they were given half and hour minutes time to give the answers for each situation for the speech act under study. At the end, all the questionnaires were collected by the researcher.

\subsection{Data Analysis}

The analysis and categorization of the collected data by means of the questionnaire were conducted based on the disagreement taxonomy with regard to the kind and frequency of the pragmatic strategies or linguistic forms opted out by participants. Therefore, the taxonomy of Muntigl \& Turnbull (1995) was employed for the speech act of disagreement in this study. The selected taxonomy is shown below.

Table 2. Taxonomy of Disagreement: (Muntigl \& Turnbull 1995)

Strategy

1. Irrelevancy claims

2. Challenges

3 .Contradictions

4.Counterclaims

5.Contradictions counterclaims

\section{Example}

Do you want some help dear. I can come and help you to make it today.

Don't you think that it's a little loose for her

I think its wrong idea.

It's a good idea but I have better idea for you

followed

by Its not right. You have better turn left.

6 .Message abandonment

\section{Result}

In order to meet the research objective of this study, the data were collected through the Written Discourse Completion Test/Task (WDCT). The researcher examined the L2 pragmatic knowledge of Iranian intermediate learners of English by performing the speech act of disagreement in English across diverse situations. It was aimed to evaluate learners' knowledge in recognition and production of accurate and appropriate speech act strategies or linguistic forms as well as situational understanding of three factors of social power, distance 
and imposition. In so doing, they were given some situations and they had to write the answers to the situations based on what they would say verbally for each scenario.

The following table illustrates the descriptive results based on frequency of the speech act' strategies and the corresponding percentage in each situation. As it was mentioned before, some items of the questionnaires differ in terms of social distance, power and rank of imposition to tap learners' awareness in using various strategies.

Table 3. Percentage of disagreement strategies across all situations

\begin{tabular}{lccccccccccc}
\hline Situations & $\mathbf{1}$ & $\mathbf{2}$ & $\mathbf{3}$ & $\mathbf{4}$ & $\mathbf{5}$ & $\mathbf{6}$ & $\mathbf{7}$ & $\mathbf{8}$ & $\mathbf{9}$ & $\mathbf{1 0}$ & Total \\
\hline Strategies & $\mathrm{P}$ & $\mathrm{P}$ & $\mathrm{P}$ & $\mathrm{P}$ & $\mathrm{P}$ & $\mathrm{P}$ & $\mathrm{P}$ & $\mathrm{P}$ & $\mathrm{P}$ & $\mathrm{P}$ & $\mathrm{P}$ \\
1.Irrelevancy & 1.4 & - & 2 & 3 & 4.6 & 5.6 & 3.1 & 10.7 & - & 3.5 & 3.2 \\
2.Challenges & 19 & 6 & 2 & 10 & 10.9 & 5.6 & 12.6 & 3.5 & 8.3 & 7 & 8.8 \\
3.Contradictions & 25 & 21 & 11 & 28 & 15.6 & 3.7 & 33.3 & 16 & 18 & 3.7 & 18.6 \\
4.Conterclaims & 28 & 57 & 77 & 32 & 57.8 & 67.9 & 30.1 & 32.1 & 43 & 1.5 & 44.8 \\
5.Contradictions & 20 & 6 & 2 & 22 & 4.6 & 5.6 & 6.3 & 12.5 & 8.3 & 5.2 & 9.7 \\
+ & & & & & & & & & & & \\
$\quad$ Conterclaims & & & & & & & & & & & \\
6.Message & 7 & 10 & 6 & 5 & 6.2 & 11.3 & 14.2 & 25 & 22.2 & 43 & 14.7 \\
$\quad$ abandonment & & & & & & & & & & & \\
Total & $.00 \%$ & 100 & 100 & 100 & 100 & 100 & 100 & 100 & 100 & 100 & 100 \\
\hline
\end{tabular}

The respondents used a variety of strategies to show disagreement. 10 situations for disagreement strategies were elicited from learners' responses in WDCT. Six situations (1, 2, $5,6,8,9)$ were the same in terms of social distance power and imposition but other situations varied with regard to the mentioned factors. A closer look at the table reveals that respondents' most frequent strategy use refers to counterclaims with $44.8 \%$. On the other hand, challenges with $8.8 \%$ and Irrelevancy of claims with $3.2 \%$ were respectively among the least frequent strategies used in all situations.

Considering each situation individually, the results showed that the most opted out strategy was counterclaim. Six situations, i.e, 1, 2, 5, 6, 8, 9 were the same regarding the contextual variables of social power, distance and imposition. The most frequently used strategy in all of these six situations was counterclaim with $27.5 \%, 57.1 \%, 57.8 \%, 67.9 \%, 32.1 \%$ and $43 \%$ for situations one, two, five, six, eight and nine respectively. An interesting finding is that although in all of the six situations the respondents were required to disagree with a friend, they contradicted a friend's opinion in situations 1,2 and 5 as the second most opted out strategy but in situations six, eight and nine, they abandoned any statements. So, message 
abandonment was used as the second most frequently chosen strategy. The least used strategy in all of these situations was irrelevancy claims.

With regard to situations three, seven, and ten which respondents were asked to disagree with a higher-status person (teacher and landlord), they mostly made use of counterclaim strategy for the three situations (situation three with $77.3 \%$, situation seven with $33.3 \%$ and situation ten with $43 \%$ ). It should be mentioned that counterclaim strategy is less direct than contradictions and challenges. In all of three situations, the least strategy used by respondents was irrelevancy claims. Regarding situation four which respondents were required to disagree with a roommate mistake about her turn to clean the room, they made use of counterclaim strategy as the most used and irrelevancy claims as the least used strategies in this situation. As a whole, the results showed that learners almost utilized the same strategies in different disagreement situations with the same frequency. Therefore, it indicates that they did not notice the situational variables to vary their choice of strategy. In other words, they did not have the contextual understanding of the mentioned factors. The following bar graph visualizes the percentage of each strategy used. It shows the most used strategy to the least one.

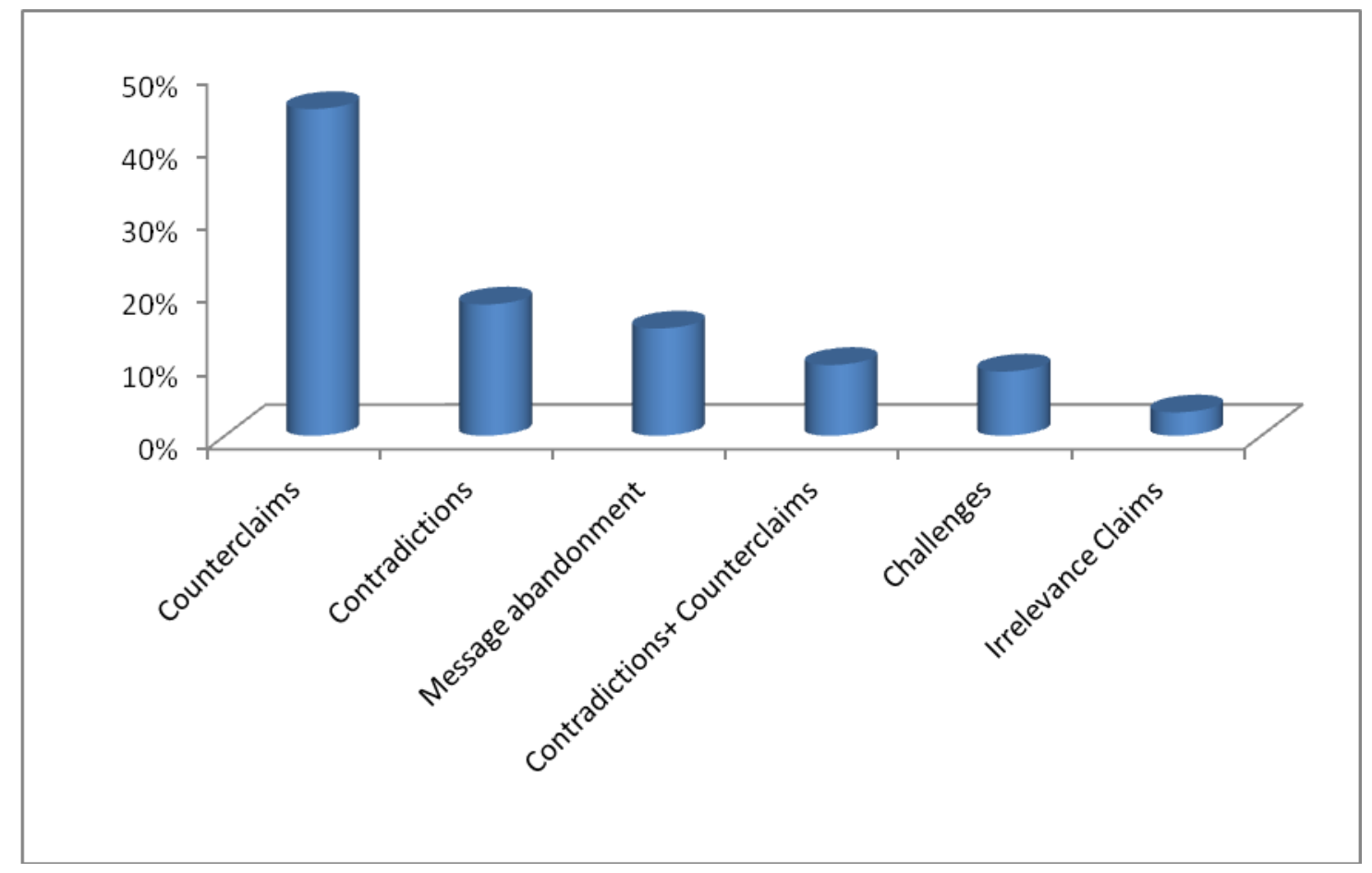

Figure 1. Disagreement strategies across all the situations

This bar graph shows the most used strategy to the least one. As the figure shows, counterclaims with $44.8 \%$ was among the most opted out strategy while the irrelevance claims with $3.2 \%$ was the least used strategy among the six strategies. 


\section{Discussion and Conclusion}

The results showed that the respondents' most frequent strategy use refers to counterclaims with $44.8 \%$. On the other hand, challenges with $8.8 \%$ and Irrelevancy of claims with $3.2 \%$ were respectively among the least frequent strategies used in all situations. The results showed that learners almost utilized the same strategies in different disagreement situations with the same frequency. Therefore, it indicates that they did not notice the situational variables of social power, distance and imposition to vary their choice of strategy. In other words, they did not have the contextual understanding of the mentioned factors. This finding can be explained with regard to two theories (politeness theory) and SLA theory (Schmidt's Noticing Hypothesis).

The finding of this research is not in harmony with politeness theory because as Brown and Levinson (1987) claimed, when producing the face-threatening acts, the interlocutor should pay attention to the three situational variables of social distance, social power and imposition. The face-threatening speech act studied in this study was disagreement. In effect, the relationship between the use of language and these three factors is a direct one. The findings of this study illustrated that the Iranian EFL learners almost chose the same pragmatic strategies to disagree with different persons (higher, an equal and a lower status person). In other words, it seems that they did not pay attention the three situational variables of social distance, power and imposition or they may not aware of them.

In addition, according to Schmidt's noticing hypothesis (1995:30), two levels of noticing and understanding of pragmatic features are identified, noticing and understanding. "Noticing refers to the conscious registration of the occurrence of some event, while understanding implies "the recognition of some general principle, rule, or pattern. Noticing refers to surface level phenomena and item learning, while understanding refers to deeper level (s) of abstraction related to (semantic, syntactic, or communicative) meaning, system learning".

In the area of pragmatics, noticing is an awareness that a speakers says this statement to his/her hearer in a special context or circumstance "I am really sorry to bother you, but if you have enough time, could you give me a hand?" . Understanding is pertinent to relating various forms by taking into consideration the politeness issue and noticing their co-occurrence with the contextual factors such as social distance, power, level of imposition.Therefore, it can be discussed that the learners may just have reached the level of noticing to choose a linguistic strategy and perform the disagreement. Therefore, they did not take into consideration and understood the situational factors since they are underlying factors to be considered in the choice of appropriate strategy or linguistic form. In other words, they have not reached to the deeper levels of abstraction and rule learning.

Other factors that may contribute to learners' lack of pragmatic knowledge (both prgmalinguistics and sociopragmatics) are implicit and inductive instruction of pragmatic features, lack of appropriate and sufficient input, output and feedback, learners' individuality and cultural identity, the nature of the speech acts and their functionality.

Pragmatic features are taught mostly implicitly and inductively in Iranian private language 
institutes. In other words, instructors make use of implicit and inductive approaches to integrate interlanguage pragmatics in their classroom practices. Therefore, learners' lack of sociopragmatic knowledge can be justified by this fact that while implicit teaching may just induce the noticing of pragmalinguistic forms, the explicit instruction may also develop the understanding of sociopragmatic rules governing these forms (Nguyen et al.2012). Moreover, it is claimed that although inductive and deductive instructions are influential for the development of pragmalinguistic knowledge, only the deductive approach leads to gains for developing the sociopragmatic competence (Dastjerdi \& Farshid, 2011; Martinez-Flor \& Fukuya, 2005; Rose \& Ng, 2001; Takahashi, 2001). Therefore, one can infer that Iranian EFL learners' lack of sociopragmatic knowledge can be attributed to implicit/inductive teaching of language functions.

Another factor that may have contributed to the weak performance of Iranian EFL learners can be the lack of appropriate and sufficient input, practice and feedback. The inappropriate use of some linguistic forms or syntactic structures (e.g. the overuse of counterclaims in all situations) can be justified by this fact that learners' pragmatic development (both pragmalinguistic and sociopragmatic knowledge) in terms of appropriate use of speech acts' strategies in different situations by considering the socio-cultural constraints depend on the provision of input, practice, and feedback ( Khodareza \& Lotfi, 2012). As Ellis (1996) claimed, the acquisition of the frequently occurred features in the input is easier than infrequently occurred features.

Moreover, in this regard, Kasper (1996b: 19) maintains that "one of the causes of learners' weak pragmatic performance is the incomplete or misleading input provided by pedagogical materials". Therefore, the basic concern of the classroom instruction should be the presentation of real and representative language to learners. However, classroom communications often "produce a limited range of speech acts, simplified openings and closings, a lot of politeness marking, and a limited range of discourse markers in the classroom discourse. For example, Mir (1992) found that instructional materials sometimes stress one linguistic form or strategy more than others which encourage the overuse of some formula than others inappropriately. Therefore, providing an appropriate and sufficient input from teaching materials, i.e., textbooks, opportunities for the practice of the target features and feedback are necessary for the development of Iranian EFL learners' pragmatic knowledge in general and speech acts in particular.

Another factor worth mentioning is the role of learners' individuality and cultural identity on the pragmatic performance. In producing the speech act, some learners tended not to perform the speech act or they performed the speech act with some new semantic formula. This matter can point to this fact that not all of the EFL learners tended to perform pragmatically like the English native speakers of the language (Washburn, 2001). In fact, L2 learners may not wish to gain native speaker pragmatic competence but they may just become competent L2 users and have enough mastery to make use of target language appropriately while keeping their cultural identity and subjectivity ( Hinkel 1996; Sigal, 1996). It means that the target language may just function as a means for interaction or communication not as a language for identification like the first language (House, 2003). This finding is in harmony 
with Siegal (1996)'s study which American female learners of Japanese refused to acquire diverse pragmatic markers. Therefore, EFL learners' individuality, their autonomy of choices with regard to the speech acts' strategies, and their values and beliefs should be acknowledged and respected by teachers.

In addition, it is of significance that learners should become aware of different choices suggested by the pragmatics system of the L2 and they should not be forced to choose with regard to the offered options. In the process of learning L2, learners may wish to make actively a novel interlanguage and concomitant identity. In this regard, learners' views about themselves can shape their desire to follow the pragmatic norms of native speakers or reject native speakers' pragmatic conventions. Furthermore, L2 learners' social status in the target language society and in different contexts of the wider L2 setting and also their experience in different interactions with native speakers can contribute to the acknowledgment or the rejection of native speakers' norms and conventions ( Eslami- Rasekh, 2005).

The nature of speech acts can have an impact on learners' choice or lack of choice of pragmatic strategies. Some speech acts are more complex and difficult for learners. For example, the production of the speech acts of apology and request is easier for learners than disagreement or giving advice (Nguyen, 2011).

Finally, the multifunctionality of some speech acts can contribute to their inappropriate or wrong choice of speech acts by learners. For example, in some cases, learners used the wrong speech act. In some cases, they performed the refusal or agreement instead of disagreement. The fact is that there is no clear and direct relationship between a semantic formula and a specific function. Therefore, in order to understand a speaker's intention, one should pay attention to the context. As a matter of fact, the multifunctionality of speech acts is considered as a necessary construct of pragmatic competence (Rose, 1999; Thomas, 1995).

With regard to learners' performance on the speech act of disagreement, the WDCT results showed that Iranian EFL learners mostly made use of counterclaims (44.8\%) strategy as an indirect strategy to disagree to higher, equal and lower-status individual in all the situations. On the other hand, irrelevancy claims (3.2\%) constitute the least frequently utilized strategy among other strategies. Such finding is in contrary to that of Vera (2010) who found that Argentine speakers of English in business meetings drew on contradictions and challenge strategies to voice their disagreement. Likewise, Sofwan (2011) showed that Indonesian learners of English realized the disagreement by means of contradiction. Moreover, the findings illustrated that three situational variables of power status, social distance and imposition did not have effects on learners' choice of disagreement strategies. The interpretation is that although learners do pay attention to the context in opting out and performing the speech acts' strategies in their first language (L1), they may not so context-sensitive and consider the situational features in their L2 (Rose and Kasper 2001).

Based on the results of this study, it is suggested that although learners'L2 pragmatic knowledge was investigated by means of WDCT, future studies can utilize other data collection instruments such as role-plays or other tasks. In addition, the politeness strategies examined in this study were power, social distance, and imposition of the task. Further 
studies can investigate other politeness strategies or situational factors, such as age and gender of interlocutors in situations.

\section{References}

Allami, H., \& Naeimi, A. (2011). A cross-linguistic study of refusals: An analysis of pragmatic competence development in Iranian EFL learners. Journal of Pragmatics, 43, 385-406. http://dx.doi:10.1016/j.pragma.2010.07.010

Al-Zumor, A. W. Q. G. (2011). Apologies in Arabic and English: An interlanguage and cross-cultural study: Journal of King Saud University Languages and Translation, 23(1), 19-28. http://dx.doi:10.1016/j.jksult.2010.02.001

Austin, J. L. (1962). How to do things with words. Oxford: Oxford University Press.

Brown, P., \& Levinson, S. C. (1987). Politeness: Some universals in language usage. Cambridge: Cambridge University Press.

Dastjerdi, H., \& Farshid, M. (2014). The role of input enhancement in teaching compliments. Journal of Language Teaching and Research 2(2), 460-466. http://dx.doi:10.4304/j1tr.2.2.460-466

Derakhshan, A., \& Zangoei, A. (2014). World Applied Sciences Journal, 31(9), 1652-1660. http://dx.doi.org/: 10.5829/idosi.wasj.2014.31.09.102

Dörnyei, Z. (2007). Research Methods in Applied Linguistics. Oxford: Oxford University Press.

Ellis, R. (1996). Interpretation tasks for grammar teaching. TESOL Quarterly, 29, 87-105.

Eslami-Rasekh, Z. (2005). Raising the pragmatic awareness of language learners. ELT Journal, 59(3), 199-208.

Farhady, H., Sajadi Hezaveh, F., \& Hedayati, H. (2010). Reflections on foreign language Education in Iran. TESL-EJ, 13(4), 1-18.

Gahrouei, V. (2013). A sociolinguistic study of speech act of suggestion in persian EFL learners. The Iranian EFL Journal, 9(1), 241-249.

Hinkel, E. (1996). Appropriateness of advice: DCT and multiple choice data. Applied Linguistics, 18(1), 1-23.

House, J. (2003). English as a lingua franca: A threat to multilingualism? Journal of Sociolinguistics, 7(4), 556-578.

Kachru, B. B. (1996). Standards, codification, and sociolinguistic realism: The English language in the outer circle. In Randolph Quirk \& Henry G. Widdowson (Eds.), English in the World, pp. 11-34. Cambridge: Cambridge University Press.

Kasper, G. (1996). Developmental issues in interlanguage pragmatics. Studies in Second Language Acquisition, 18, 149-169. 


\section{Al Macrothink}

International Journal of Linguistics

ISSN 1948-5425

2016, Vol. 8, No. 5

Khodareza, M., \& Lotfi, A. R. (2013). Interlanguage pragmatic development: The effect of formal instruction on Iranian EFL learners' interpretation and use of speech act of apology. Asian Journal of Social Sciences and Humanities, 2(2), 99-104.

Kia, E., \& Salehi, M. (2013). The effect of explicit and implicit instruction of English thanking and complimenting formulas on developing pragmatic competence of Iranian EFL upper-Intermediate level learners. Journal of Basic and Applied Scientific research, 3(8), 202-215.

Kreutel, K. (2007). I'm not agreeing with you.'ESL learners' expressions of disagreement. TESL-EJ, 11(3), 21-30.

Lin, M. F. (2014). An Interlanguage pragmatic study on Chinese EFL learner's refusal: Perception and performance. Journal of Language Teaching and Research, 5(3), 642-653. http://dx.doi.org/10.4304/jltr.5.3.642-653

Martinez-Flor, A., \& Fukaya, Y. J. (2005). The effects of instruction on learners' production of appropriate and accurate suggestions. System, 33(3), 463-480.

Mir, M. (1992). Do we all apologize the same? An empirical study on the act of apologizing by Spanish speakers learning English. Pragmatics and Language Learning, 3, 1-19.

Muntigl, P., \& Thrnbull, W. (1998). Conversational structure and facework in arguing. Journal of Pragmatics, 29, 225- 256.

Nguyen, M. T. T. (2011). Learning to communicate in a globalized world: To what extent do school textbooks facilitate the development of intercultural pragmatic competence? RELC Journal, 42(1), 17-30.

Nguyen, M. T. T., Pham, T. H., \& Pham, M. T. (2012). The relative effects of explicit and implicit form-focused instruction on the development of L2 pragmatic competence. Journal of Pragmatics, 44, 416-434.

Rose, K., \& Ng, C. (2001). Inductive and deductive teaching of compliments and compliment responses. In Kenneth R. Rose \& Gabriele Kasper (Eds.), Pragmatics in Language Teaching, pp. 145-170. Cambridge: Cambridge University Press.

Rose, K. R., \& Kasper, G. (ed.). (2001). Pragmatics in language teaching. Cambridge: Cambridge University Press.

Rose, K. R. (1999). Teachers and students learning about requests in Hong Kong. In: Edvard Hinkel (ed.). Culture in Second Language Teaching and Learning, pp. 167-180. Cambridge: Cambridge University Press.

Sabzalipour, B. (2013). The effect of using web-based instruction on learning of speech act of compliment of Iranian EFL learners. Asian Journal of Management Sciences and Education, 2(3), 11-19.

Salehi, M. (2013). The effect of instruction on the development of pragmatic competence. International Journal of Social Science Research, 1(2), 86-97. 
http://dx.doi.org/10.14239/IJSSR.2013.01203

Schmidt, R. (1995). Consciousness and foreign language learning: A tutorial on the role of attention and awareness in learning. In Richards Schmidt (Ed.), Attention and Awareness in Foreign Language Learning, pp. 1-63. Honolulu, HI: University of Hawaii, Second Language \& Curriculum Center.

Siegal, M. (1996). The role of learner subjectivity in second language sociolinguistic competency: Western women learning Japanese. Applied Linguistics, 17, 356-382.

Sofwan, A., \& Suwignyo, E. (2011). The realization of disagreement strategies by non-native speakers of English. Journal of Language and Literature, 1, 41-56.

Takahashi, S. (2001). The role of input enhancement in developing pragmatic competence. In Kenneth R. Rose, \& Gabriele Kasper (Eds.), Pragmatics in Language Teaching, pp. 171-199. Cambridge: Cambridge University Press.

Tamjid, N., \& Noroozi, M. (2014). The effect of pragmalinguistic focus on form on Iranian EFL learners' production of refusal forms: with a focus on marked recasts and elicitation. International Journal of Applied Linguistics and English Literature, 3(2), 53-63. http://dx.doi.org/10.7575/aiac.ijalel.v.3n.2p.53

Thomas, J. (1995). Meaning in interaction. An introduction to pragmatics. New York: Longman.

Washburn, G. N. (2001). Using situation comedies for pragmatic language teaching and learning. TESOL Journal, 10(4), 21-26.

\section{Copyright Disclaimer}

Copyright for this article is retained by the author(s), with first publication rights granted to the journal.

This is an open-access article distributed under the terms and conditions of the Creative Commons Attribution license (http://creativecommons.org/licenses/by/3.0/). 